\title{
PERFORMANCE ANALYSIS OF PREFABRICATED SUBSTATION BOX IN WIND AND SNOW ENVIRONMENT AND HIGH ALTITUDE
}

\author{
Feng Zhengmao $^{1}$, Sui Xiuhua ${ }^{2}$, Wang Fengjiao ${ }^{3}$, Liu Xiaoyu ${ }^{4}$, Zhao Changzheng ${ }^{5}$, Chen Hongzhi ${ }^{6}$ \\ ${ }^{1}$ Shandong Taikai Apparatus Complete co.ltd, Taikai Group, Taian, 271000, China \\ ${ }^{2}$ College of Mechanical and Electronic Engineering, Shandong University of Science and Technology, Qingdao, \\ 266590, China \\ ${ }^{3}$ College of Mechanical and Electronic Engineering, Shandong University of Science and Technology, Qingdao, \\ 266590, China \\ ${ }^{4}$ College of Mechanical and Electronic Engineering, Shandong University of Science and Technology, Qingdao, \\ 266590, China \\ ${ }^{5}$ College of Mechanical and Electronic Engineering, Shandong University of Science and Technology, Qingdao, \\ 266590, China \\ ${ }^{6}$ College of Mechanical and Electronic Engineering, Shandong University of Science and Technology, Qingdao, \\ 266590, China
}

\begin{abstract}
Prefabricated substation are highly susceptible to external environmental and mechanical factors due to long-term exposure to the outdoors. On account of the large structure, the prefabricated substation box is difficult to conduct on-site tests and indoor test analysis. In this paper, according to the topography and climatic characteristics of north western China where prefabricated substation box is used in, finite element analysis method is developed to analyze its performance under wind and snow loads in this region, wind and snow resistance performance of prefabricated substation box is studied, which provides a new idea for the design of prefabricated substation box in the special environment and has important practical application value and research significance.
\end{abstract}

Keywords: - box, mechanics, stability, finite element method

\section{INTRODUCTION}

The prefabricated substation box is installed outdoors for a long time. In the north western part of China, where the altitude is high, and the winter is cold and long, the box is more susceptible to the erosion of heavy storms and undetermined natural forces [1], which can lead to major deformation of roof panels, columns, and door walls in severe cases. Therefore, the analysis of its performance has important practical application value and research significance.

Owing to the large structure of the prefabricated substation box, it is difficult to conduct on-site tests and indoor test analysis. The finite element analysis method is used to analyze its performance, which has important practical application value and research significance. In recent years, many scholars at home and abroad have conducted a lot of analysis and research on wind and snow resistance. Li Yue [2] made a numerical simulation of snow movement and wind-induced snow erosion-deposition. Chen Yong [3] et al. studied the seismic performance and the force performance under strong wind for the $110 \mathrm{kV}$ prefabricated substation box. Michael O'Rourke [4] analyzed the effects of parameters such as slope and width of double-sloping roof, ground snow load on the snow load. Taylor [5]et al. conducted a detailed study of the values of snow loads on roofs under different slopes, roof forms, spans, roof heights. Beyers [6] et al. simulated the snow deposition and snow drift of the cube.

The above literature analyzes the effects of roof slope, roof span and roof height on wind loads and snow loads using different methods. However, the research on performance under the combination of wind and snow loads are few. In this paper, on the basis of the topography and climatic characteristics of north western China, the performance of the box used in this area under wind and snow load conditions is analyzed, and the wind and snow resistance performance is also conducted, which provides a new idea for the design of prefabricated substation box used in the special environment.

\section{PREFABRICATED SUBSTATION BOX STRUCTURE}

The prefabricated substation designed in this paper is applied to the north western part of China, in this area the wind speed can reach up to 12 levels, and the maximum snow thickness is above $50 \mathrm{~cm}$. Therefore, the designed 
prefabricated substation box should have the ability to withstand 12 wind loads and $60-70 \mathrm{~cm}$ snow load. By calculating, the maximum wind pressure is $0.7225 \mathrm{kN} / \mathrm{m}^{2}$, and the maximum snow load is $1 \mathrm{kN} / \mathrm{m}^{2}$.

In this paper, the structural design of prefabricated substation is carried out by using the "mesh" type structure layout. In the light of the design standard and maintenance distance, the box body of the designed prefabricated substation consists of three parts: the top cover, the body case and the base. The top cover is $7700 \mathrm{~mm}$ long and $3200 \mathrm{~mm}$ wide, the length and width of both the base and the body case are $7500 \mathrm{~mm}$ and $3000 \mathrm{~mm}$, and The height of the base is $160 \mathrm{~mm}$. Three access doors are respectively arranged on prefabricated substation box[7], as shown in Figure 1 .

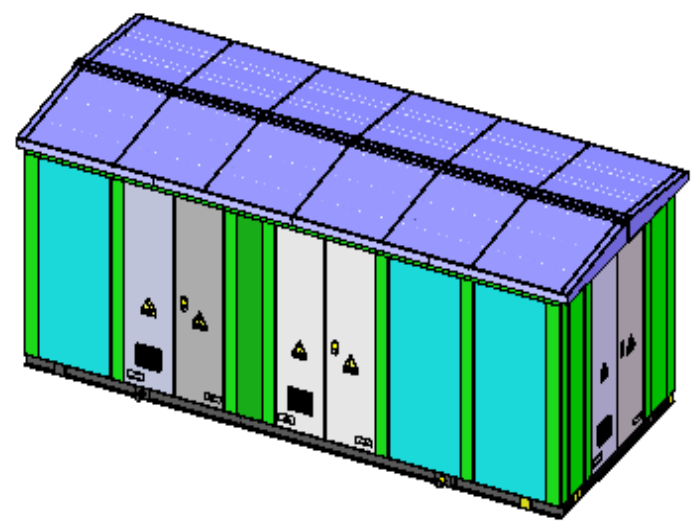

Fig 1: Assembly model
Since there are many parts in the prefabricated substation box designed in this paper, the structure is simplified, which is shown in Figure 2.

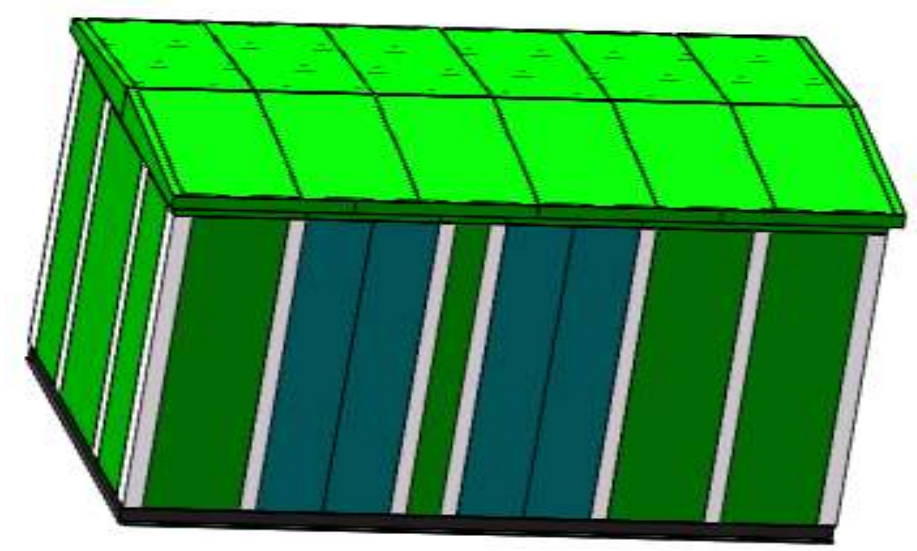

Fig 2: Simplified model

The mesh size and the relevance property of the mesh are set[8-9], and the mesh model is shown in Figure 3. This model has a total of 336,734 nodes and 130,369 units.

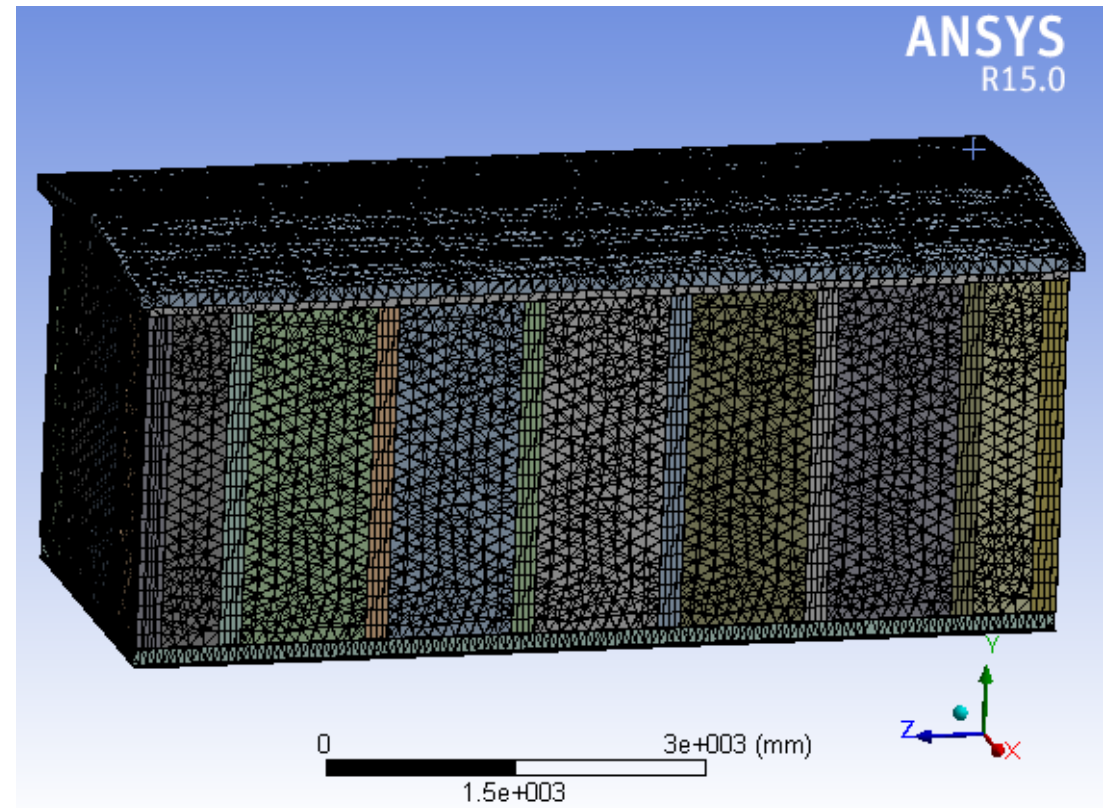

Fig 3: Grid model graph of box body in prefabricated substation

Then adding constraints and boundary conditions to the box, the weight of the box is loaded into the entire model according to the acceleration of gravity. The 10 tons equipment quality in the box is loaded onto the base, wind loads are applied to force surface, the snow load is $1 \mathrm{kN} / \mathrm{m}^{2}$ and is acted on the top cover, which is shown in Figure 4 and Figure 5. 


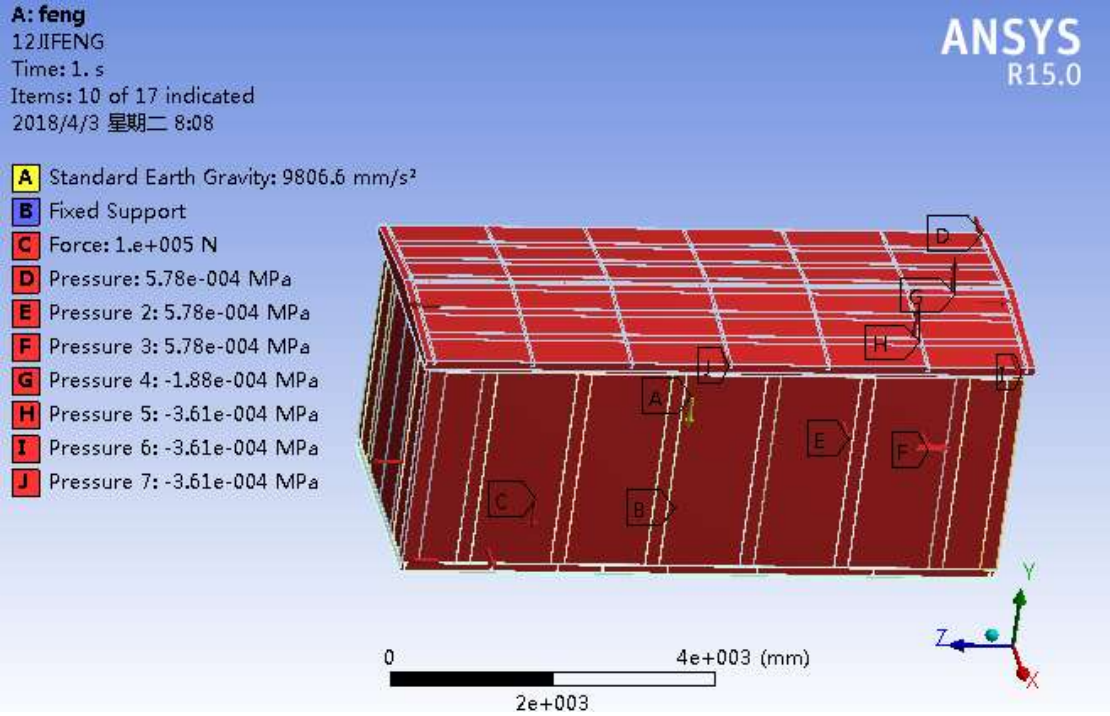

Fig 4: Boundary condition setting of wind resistance performance analysis

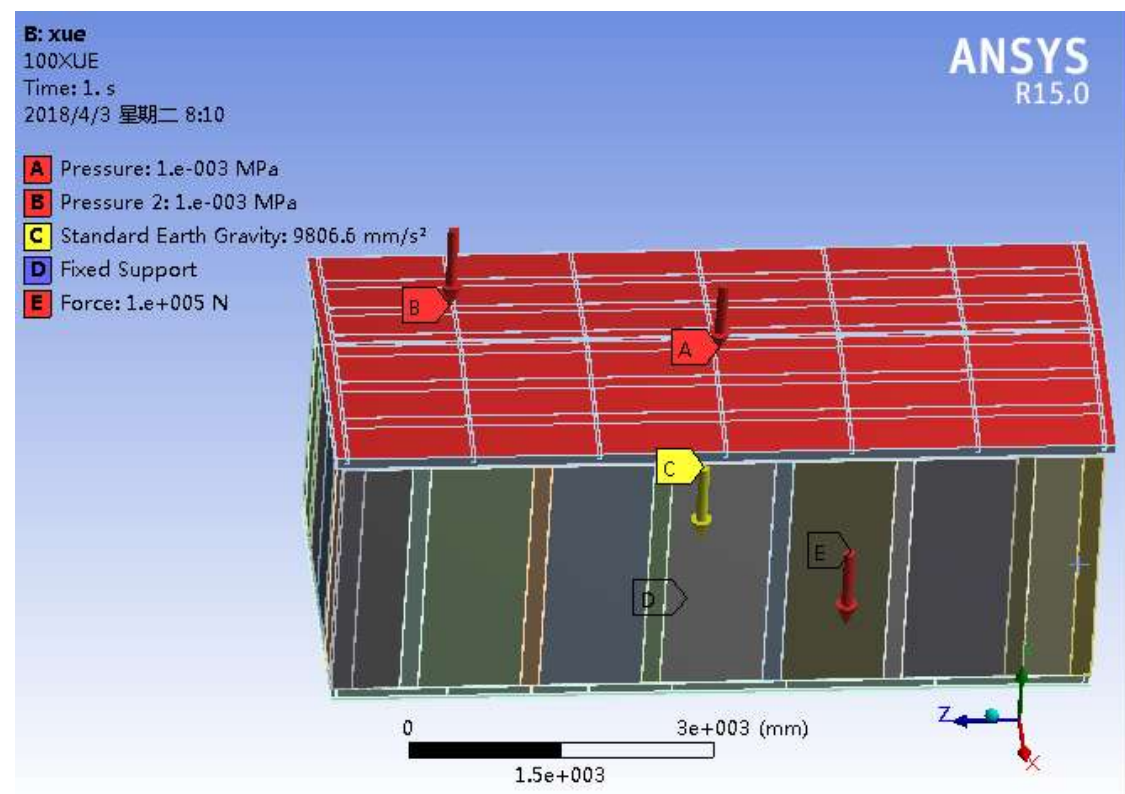

Fig 5: Boundary condition setting of snow resistance performance analysis

\section{ANALYSIS OF WIND AND SNOW \\ RESISTANCE OF PREFABRICATED SUBSTATION BOX}

\subsection{Strength Analysis under the Action of Wind}

\section{Load}

The wind pressure received at different positions of the box is loaded on the surface, the deformation trend and stress of the box type substation is obtained under the wind condition, as shown in Figure 6. The color of the deformation map from blue to red indicates that the deformation changes from small to large. Red denotes the largest part of deformation, and blue means the smallest part of deformation. 


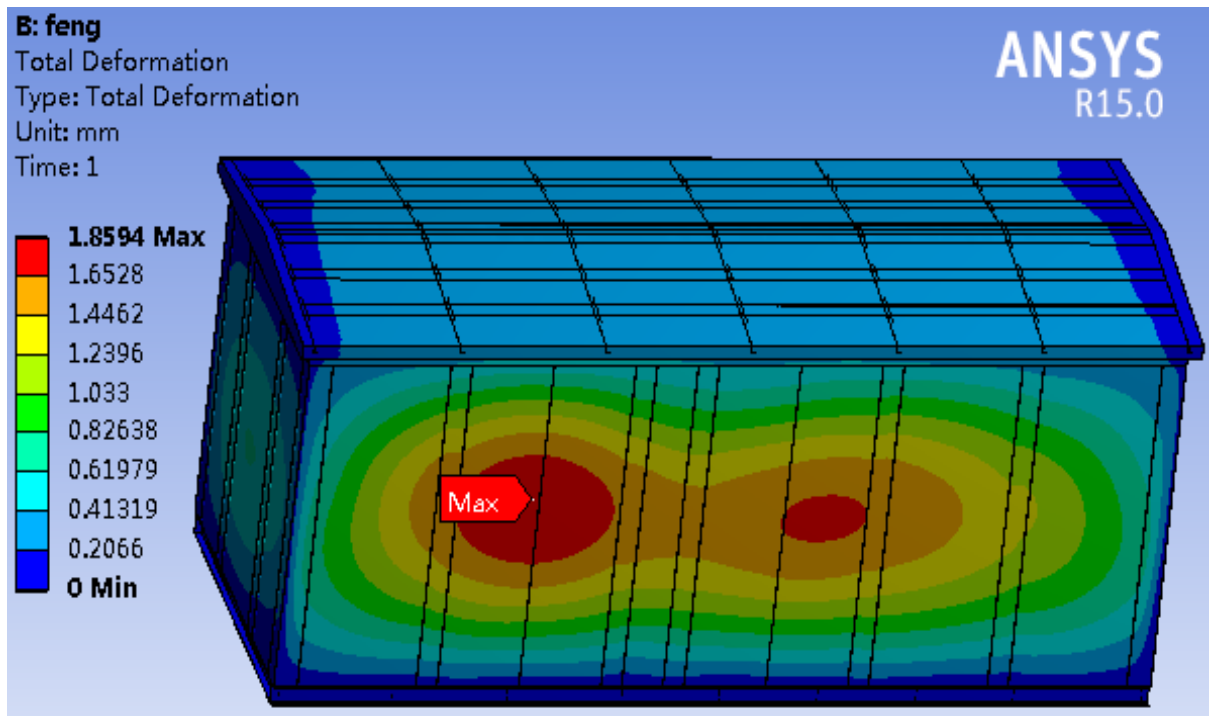

(a) Deformation cloud map

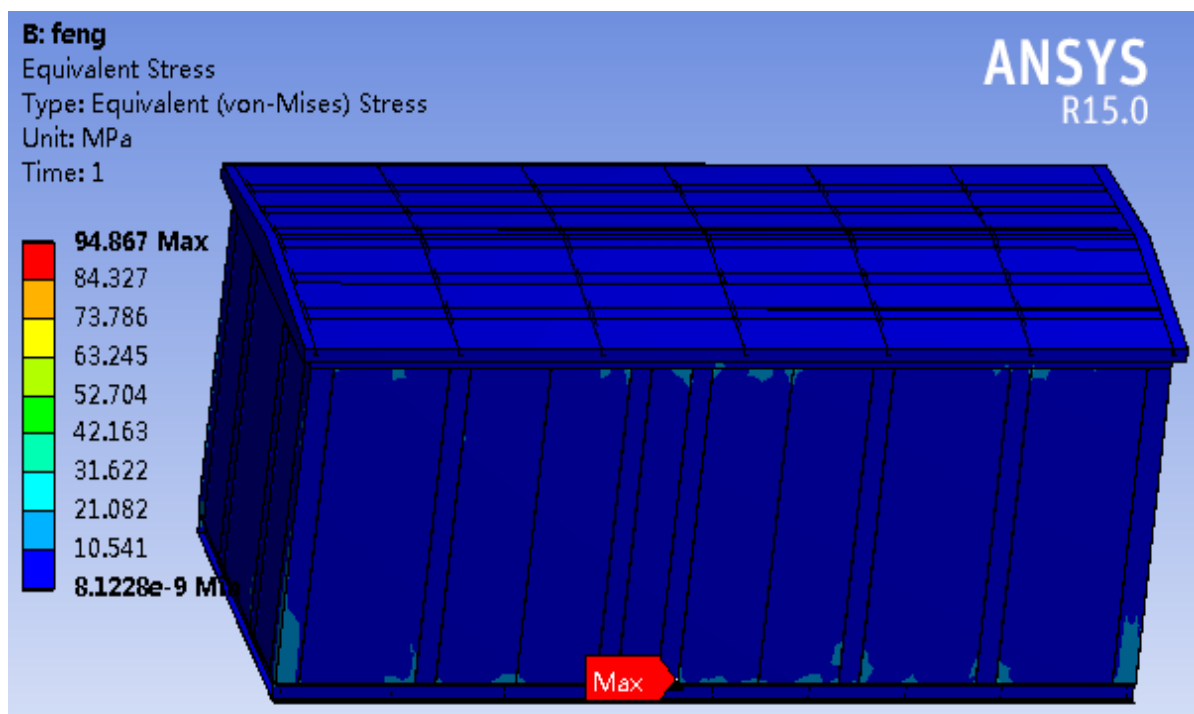

(b) Stress cloud map

Fig 6: Wind resistance performance results

As can be seen from the above figure, under the influence of wind load, the overall deformation of the windward wall is larger than that of other wall surfaces. The maximum deformation occurs at the door panel position, which is $1.8594 \mathrm{~mm}$. This is because the sum of the door panels width is larger than the width of other wall panels. In addition, due to the large spacing of the columns on both sides of the door panel, the support of the column to the door panel is weak relative to other positions, so the influence of the wind on the door panel is relatively large.

The maximum stress occurs at the junction of the windward side column and the base, which is $94.867 \mathrm{MPa}$, less than the allowable stress of the material of $140.7 \mathrm{MPa}$. Therefore, the design of the prefabricated substation box meets the strength requirements under the wind action of grade 12 .

\subsection{Strength Analysis under the Action of Snow}

\section{Load}

The snow pressure of $1 \mathrm{kN} / \mathrm{m}^{2}$ is loaded on the top cover of the prefabricated substation box, the snow resistance performance is analyzed. Figure 7 shows the deformation trend and stress state. 


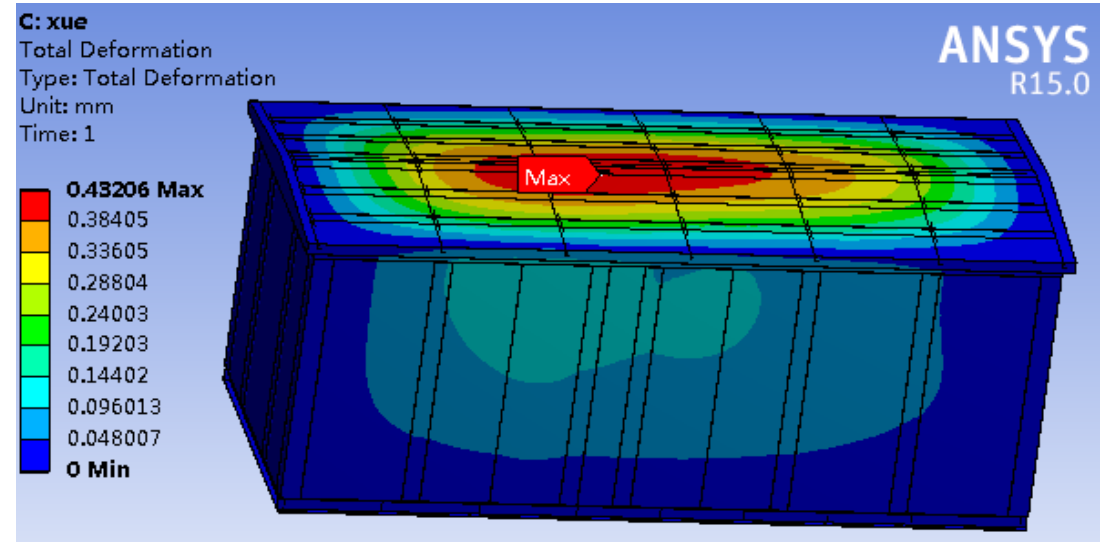

(a) Deformation cloud map

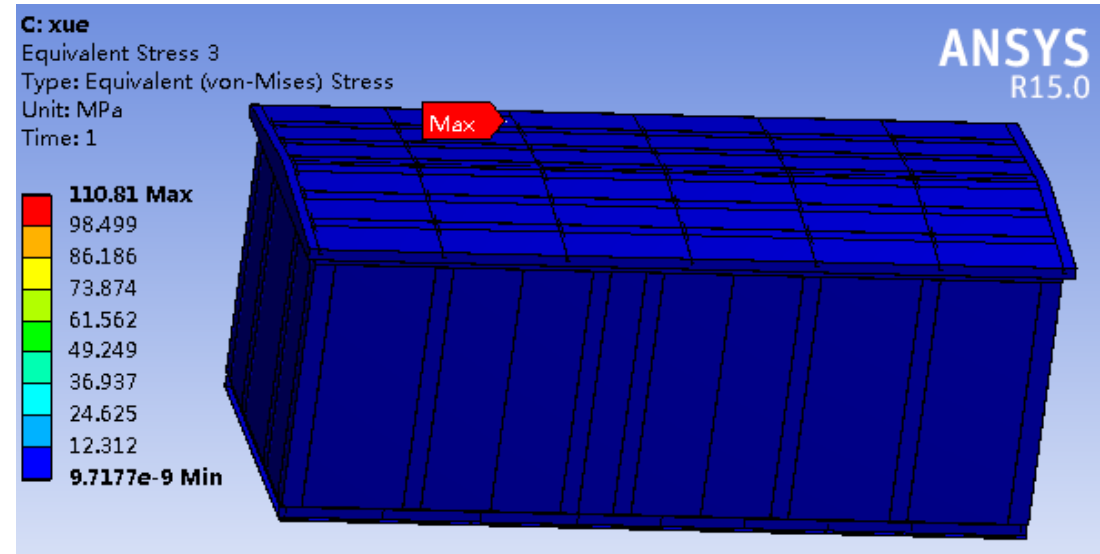

(b) Stress cloud map

Fig 7: Snow resistance performance results

It is evident from Figure 7(a) that the maximum deformation of the prefabricated substation box under the snow load occurs in the middle of the top cover, which is $0.43206 \mathrm{~mm}$. Although the middle position of the top cover is supported by beams and purlins, it is far from the gables and columns, so its supporting area is smaller than other places. It can be seen from Figure 7(b) that under the action of snow load, the maximum stress of the prefabricated substation box is at the position where the roof span beam and the roof outer eaves ring beam contact, which is $110.81 \mathrm{MPa}$, less than the allowable stress of the material, so the box of the substation meets the strength design requirements[10].

\subsection{Strength Analysis under Combined Wind and Snow Load}

We study the performance of the box when the wind and snow load work together, and obtain the deformation trend and stress state, as shown in Figure 8.

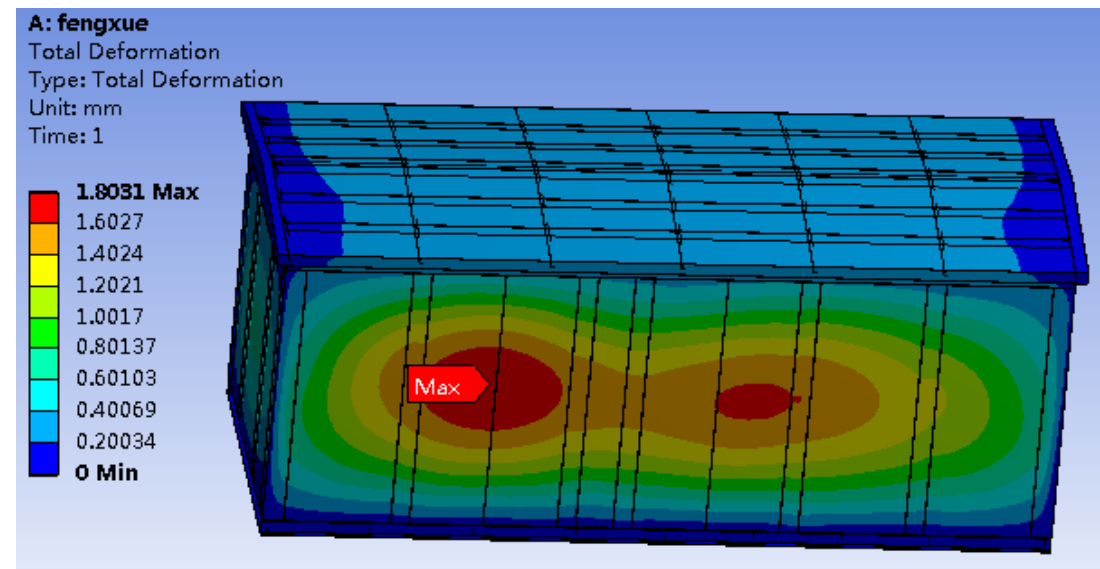

(a) Deformation cloud map 


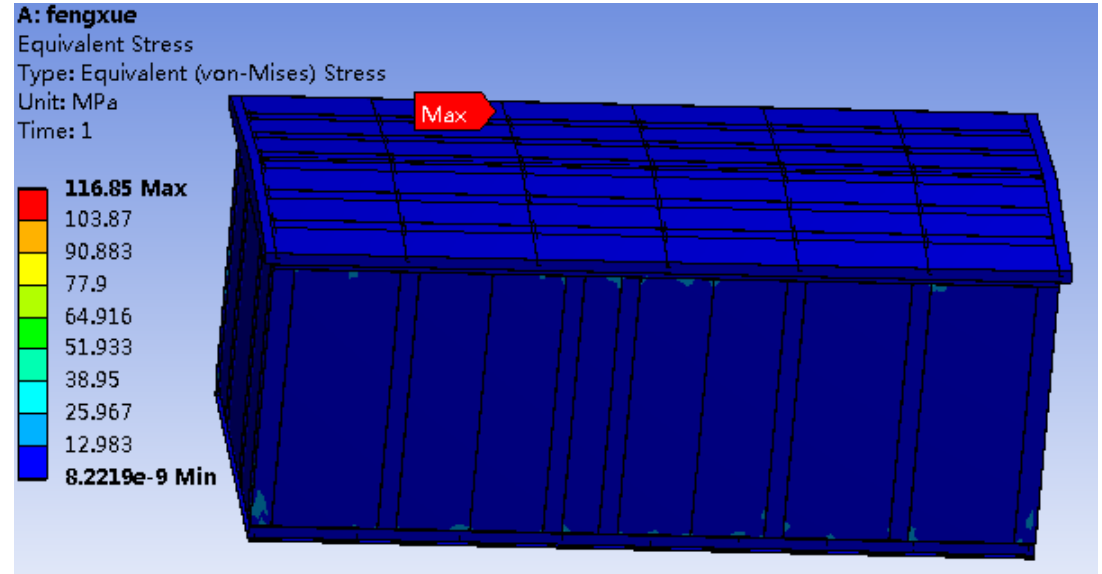

(b) Stress cloud map

Fig 8: Wind and snow resistance performance results

As can be seen from above figure that under the combined action of wind and snow loads, the maximum deformation of prefabricated substation box is at the wall panel position of the wind receiving surface, which is $1.8031 \mathrm{~mm}$. The maximum equivalent stress of the box occurs at the same position when the snow load works solely, which is 116.85 $\mathrm{MPa}$ and less than the allowable stress of the material. So the designed box structure for prefabricated substation meets the strength requirements.

\section{STABILITY ANALYSIS UNDER THE ACTION OF WIND AND SNOW LOAD}

The wall thickness of the prefabricated substation box is relatively thin, and it is easy to come into being buckling deformation under axial pressure. Based on the static analysis, the finite element method is developed to analyze the buckling deformation and study its stability. The first 6order buckling load coefficient is calculated as shown in Table-1, and the vibration mode results are shown in Figures 9, 10 and 11 .

Table 1: Buckling coefficient of prefabricated substation box

\begin{tabular}{|l|l|l|l|}
\hline Order & $\begin{array}{l}\text { Buckling coefficient } \\
\text { under wind load }\end{array}$ & $\begin{array}{l}\text { Buckling coefficient } \\
\text { under snow load }\end{array}$ & $\begin{array}{l}\text { Buckling coefficient under } \\
\text { combined wind and snow load }\end{array}$ \\
\hline 1 & 132.38 & 531.8 & 131.59 \\
\hline 2 & 135.56 & 546.58 & 134.56 \\
\hline 3 & 140.09 & 586.2 & 138.75 \\
\hline 4 & 140.69 & 587.25 & 139.95 \\
\hline 5 & 145.6 & 635.03 & 144.62 \\
\hline 6 & 147.38 & 641.87 & 145.69 \\
\hline
\end{tabular}

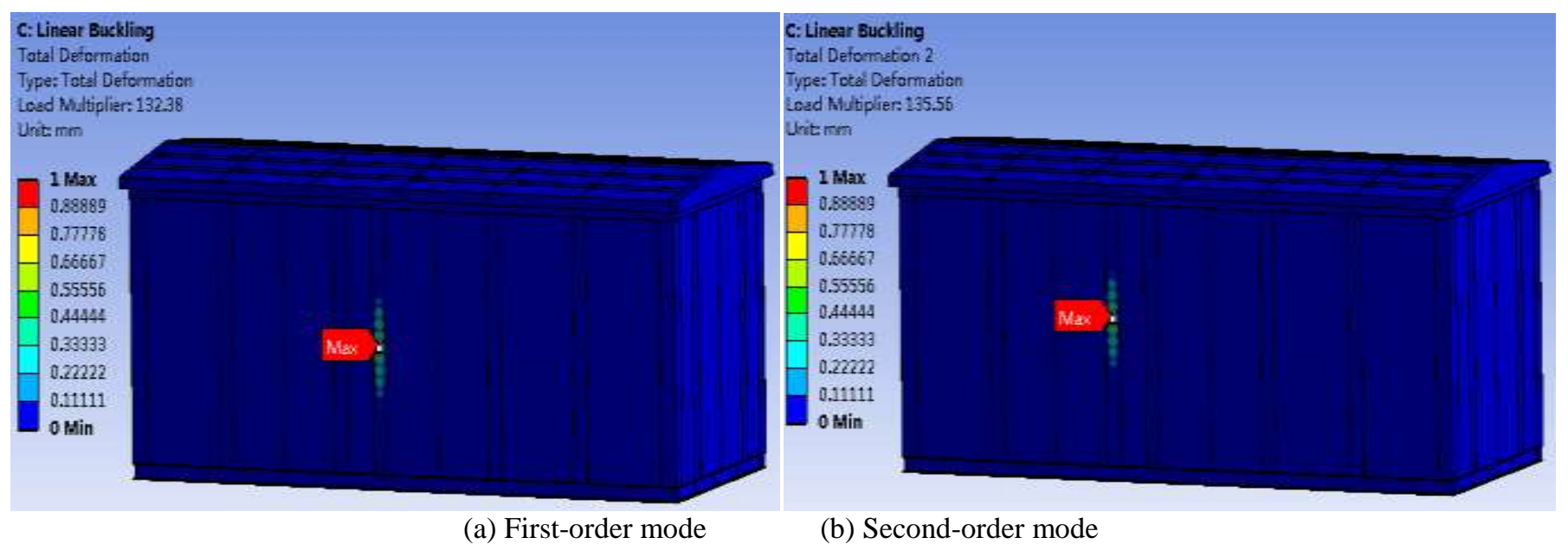




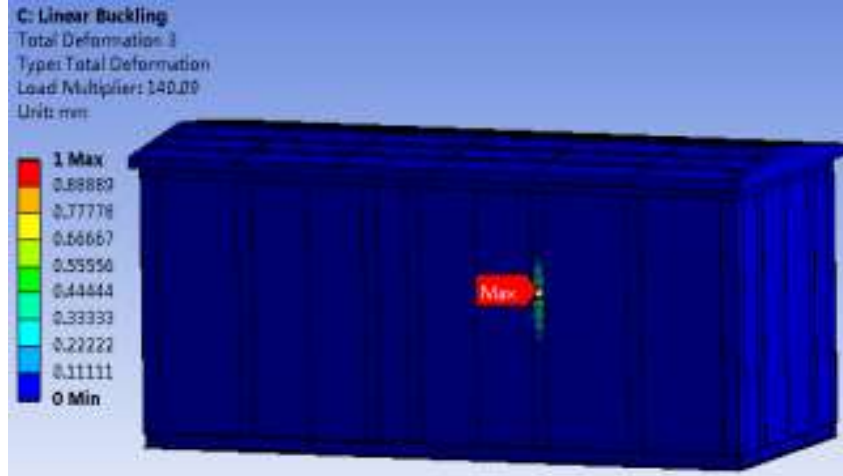

(c) Third-order mode

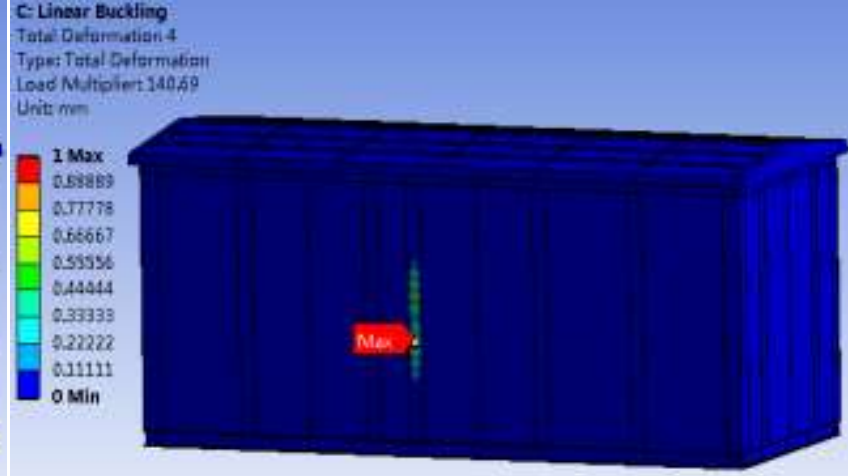

(d) Fourth-order mode

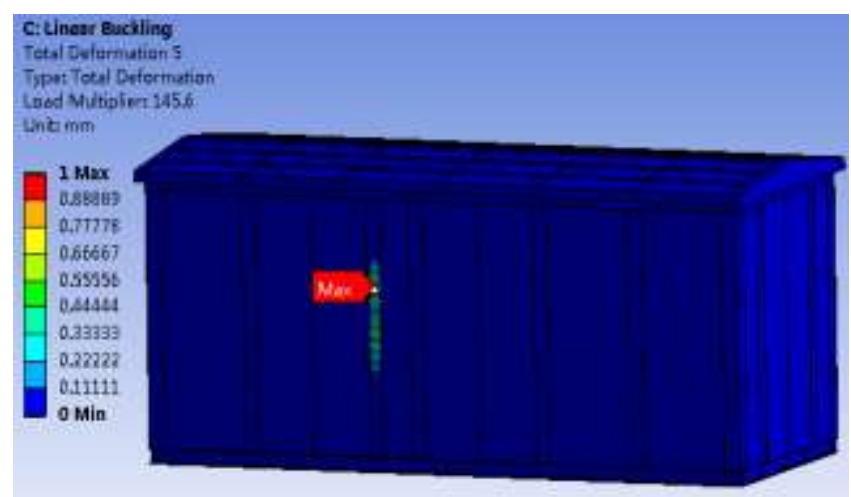

(e)Fifth-order mode

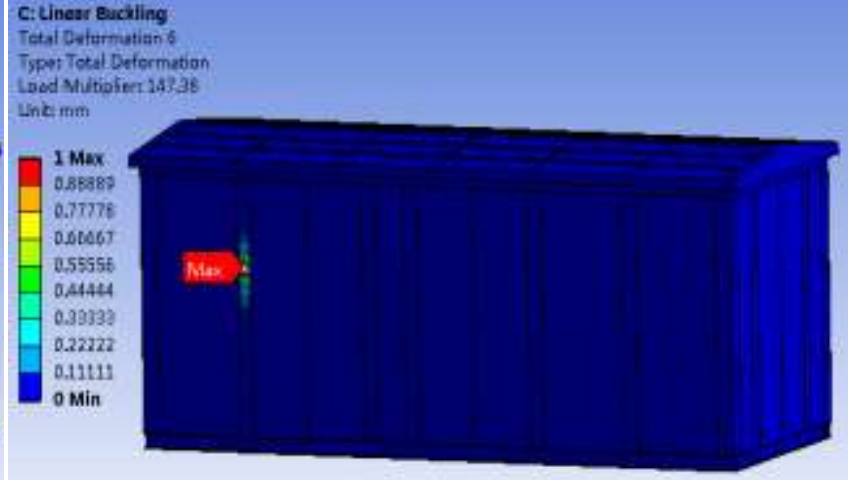

(f) Sixth-mode

Fig 9: First six modes of buckling analysis under wind load

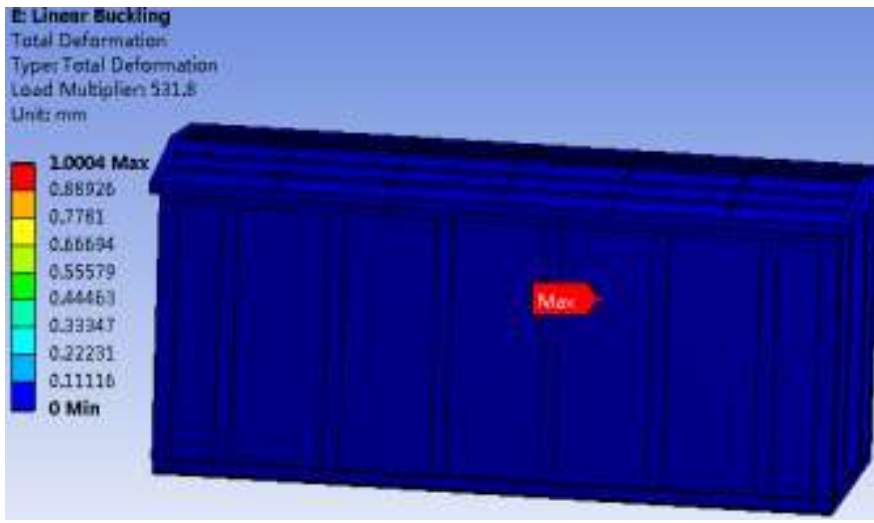

(a) First-order mode

(c) Third-order mode

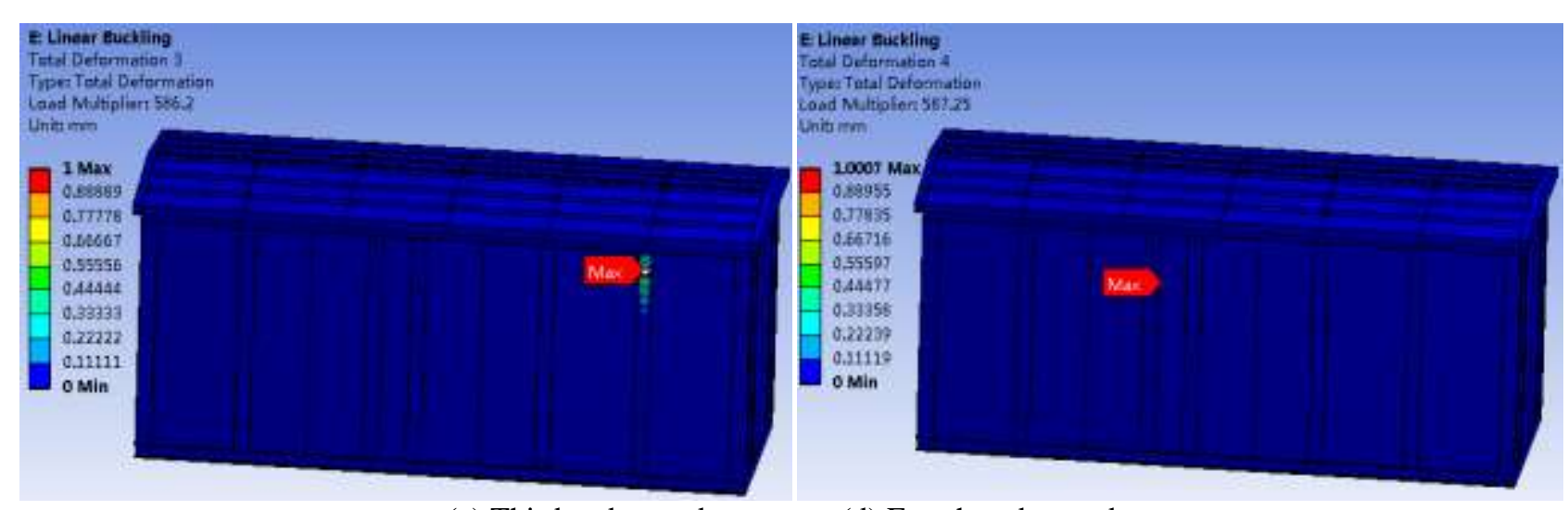

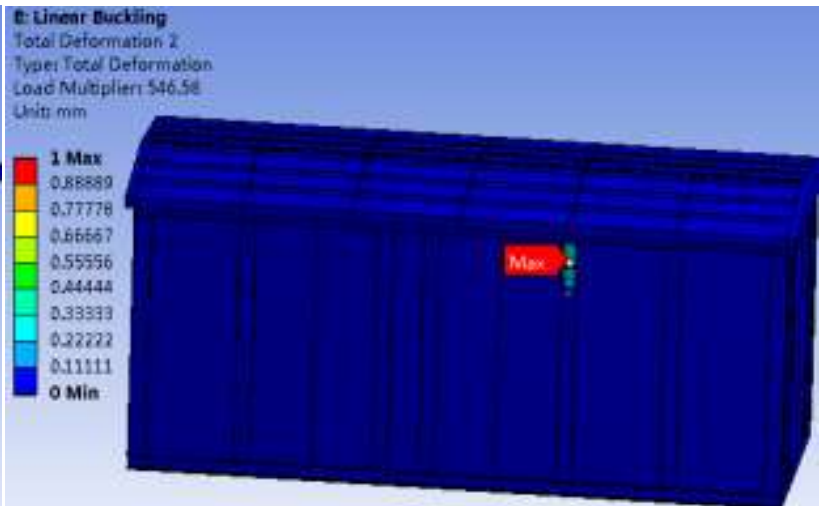

(b) Second-order mode

(d) Fourth-order mode 


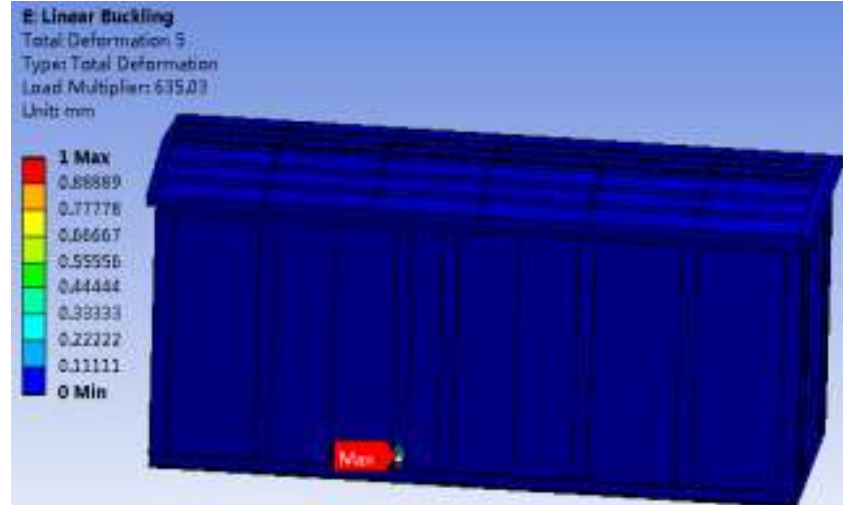

(e) Fifth-order mode

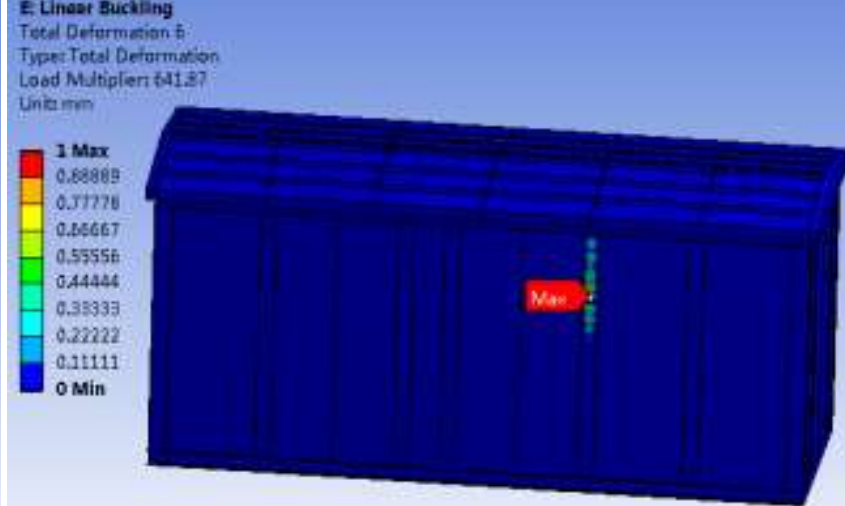

(f) Sixth-mode

Fig 10: First six modes of buckling analysis under snow load

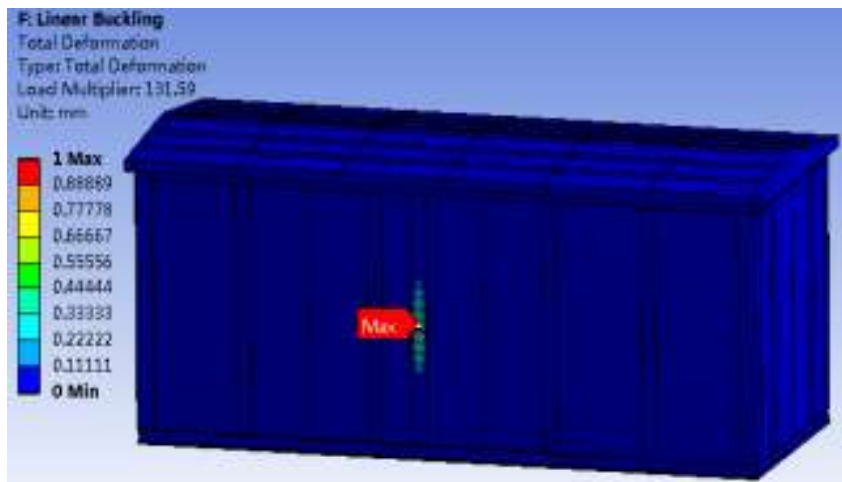

(a) First-order mode

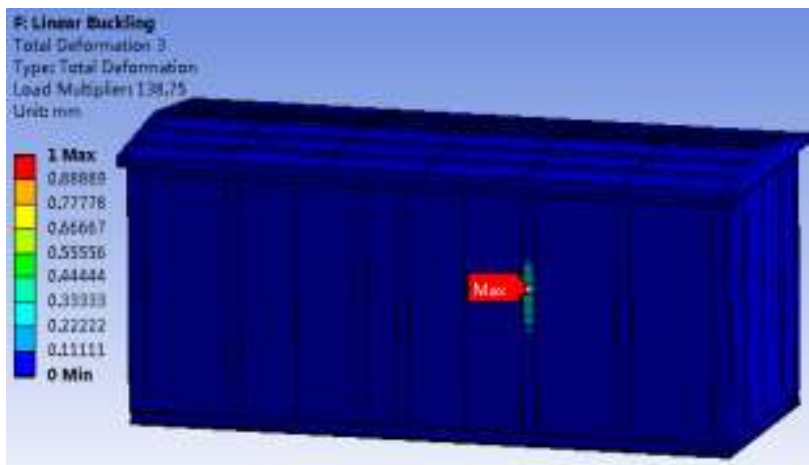

(c) Third-order mode

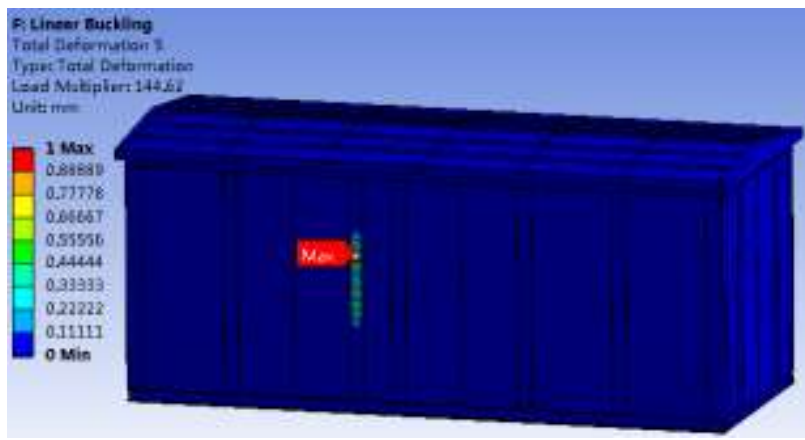

(e) Fifth-order mode

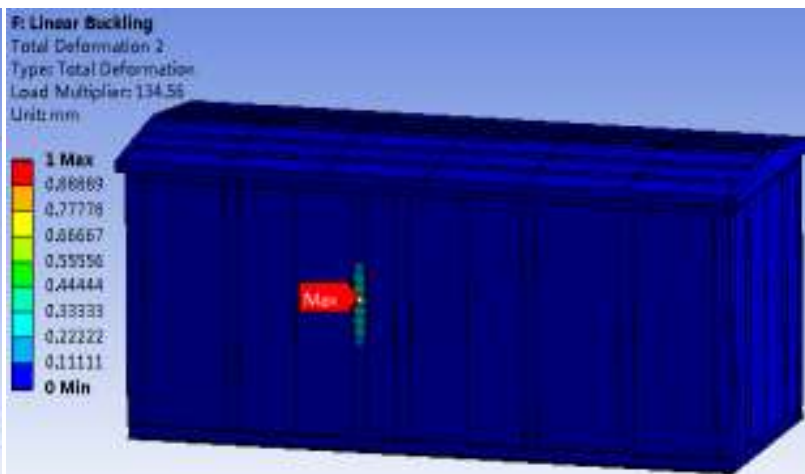

(b) Second-order mode

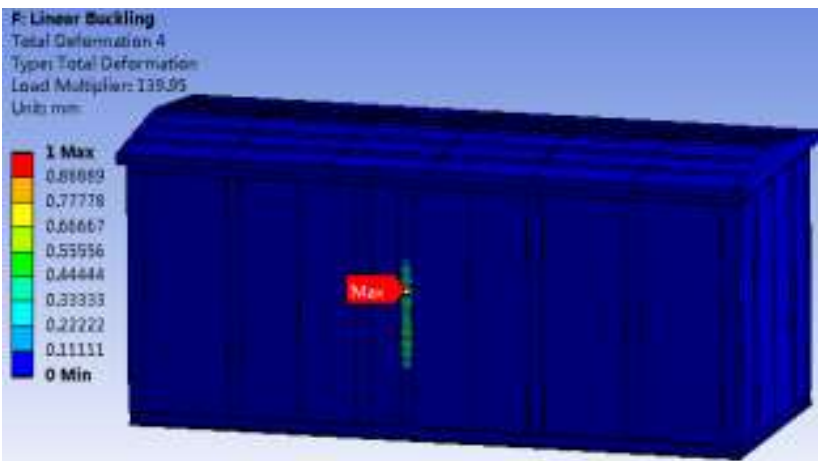

(d) Fourth-order mode

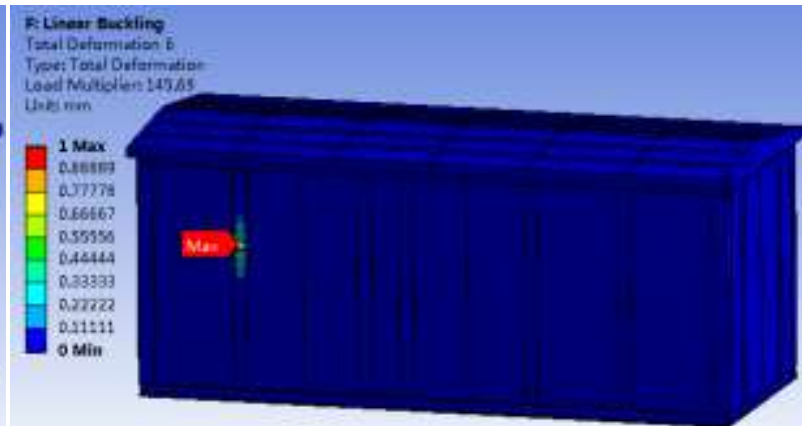

(f) Sixth-mode

Fig 11: First six modes of buckling analysis under wind and snow load 
According to Table-1 and Figures 9,10 and 11, in the buckling analysis, the buckling coefficient of the prefabricated substation box is 132.38 under the action of the wind load, is 531.8 under the snow load, and 131.59 under the combined wind and snow load, which indicates that when the load exceeds 131.59 times of the load added in this analysis, the prefabricated substation box will undergo buckling failure and become unstable. As can be seen from the first six-order mode that the most unstable position is on the column, so the overall box stability can be improved by increasing the thickness of the column or changing the column material.

\section{CONCLUSION}

According to the topography and climate characteristics of north western China, in this paper finite element analysis method is developed to analyze its performance under wind and snow loads in this region. Finite element analysis model of the box is established, wind load, snow load and combined load of wind and snow are applied to the box substation box respectively to study its strength. On this basis the box stability is analyzed. The results show that the maximum equivalent stress of the box is less than the allowable stress of the material, which meets the design requirements of the wind and snow resistance performance of the box. It has good stability and no buckling failure occurs.

\section{REFERENCES}

[1] Wei Jianxiang, Influence of high altitude snow and snow weather on electromechanical characteristics of transmission lines and insulators, North China Electric Power University, 2015.

[2] Li Yue, Snow load research on large-span spatial structure roof, Zhejiang University, 2014.

[3] Chen Yong, Dai Bin, Zhou Yunbin, Force analysis method for $110 \mathrm{kV}$ prefabricated substation box based on finite element principle, 2014 Yunnan electric power technology BBS,2014.

[4] Michael O'Rourke, Michael Auren, Snow Loads on Gable Roofs, Journal of Structural Engineering, 1997.

[5] Taylor D A, Roof snow loads in Canada, Canadian Journal of Civil Engineering, 1980.

[6] Beyers M, Waechter B, Modeling transient snowdrift development around complex three-dimensional structures, Journal of Wind Engineering \& Industrial Aerodynamics, 2008.

[7] Zhao Wei, Yang Xiaojin, Zhao Nan, Solid Works 2016 Chinese version of mechanical design from entry to the master, People's Posts and Telecommunications Press, 2016.

[8] Zhang Yan, et al. ANSYS Workbench 15.0 finite element analysis from entry to mastery, Mechanical Industry Press, 2014.

[9] Huang Zhixin, Liu Chengzhu, ANSYS Workbench 14.0 Super Learning Manual, People's Posts and Telecommunications Press, 2013.
[10] Yan Qun, Zhu Fucai, Xu Shuqin, Discussion on the difference between the theoretical values of the third and fourth strengths. Agricultural Mechanization Research, 2003 (3)

\section{BIOGRAPHIES}

Feng Zhengmao, research major: mechanical and electronic engineering, email:fengzhm@126.com

Sui Xiuhua, corresponding author, associate professor, research major: mechanical and electronic engineering, email: suixh@126.com

Wang Fengjiao, master degree student, email: 761546026 @qq.com

Liu Xiaoyu, master degree student, email: L1596638274@163.com

Zhao Changzheng, master degree student, email: 17806263313@163.com

Chen Hongzhi, master degree student, email: chenhz15650183781@163.com 